BY ROGER BEDARD, PAUL T. JACOBSON, MIRKO PREVISIC, WALTER MUSIAL, AND ROBERT VARLEY

\title{
An Overview of Ocean Renewable Energy Technologies
}

ABSTRACT. Ocean energy is a term used to describe renewable energy derived from the sea, including ocean wave energy, tidal and open-ocean current energy (sometimes called marine hydrokinetic energy), tidal barrages, offshore wind energy, and ocean thermal and salinity gradient energy. Shallow water offshore wind is a commercial technology (over 1,500 MW capacity installed in Europe). The technologies to convert the other ocean energy resources to electricity, including deepwater offshore wind technology, albeit in their infancies, exist. These technologies are ready for fullscale prototype and early commercialization testing at sea. This paper highlights the technology development status of various energy conversion technologies.

\section{INTRODUCTION}

In the 1970s, the United Kingdom had the most aggressive wave energy program in the world. Although the program contributed to important research such as optimal control and tuning of wave power conversion devices, it ultimately stalled as oil prices dropped and government funding stopped. The US Department of Energy (DOE) funded an open-ocean current program in the 1970s, an ocean thermal energy conversion (OTEC) program in the 1980s, and a wind program extending from the late 1970s to the present, which includes a small offshore wind component. There are a few tidal barrage plants: a $240 \mathrm{MW}$ plant at LaRance, France; a $20 \mathrm{MW}$ plant at Annapolis, Nova Scotia, Canada; and smaller plants in China and Russia. Tidal in-stream technology development has been funded in Europe since the 1990s, and DOE started its wave, tidal, and open-ocean current program in 2008. Salinity gradient technology has received attention in Europe, particularly in Norway and the Netherlands.

Today, a large number of small companies backed by government organizations, private industry, utilities, and venture capital are leading the commercialization of technologies to generate electricity from ocean wave and tidal/open-ocean current energy resources. A small number of large companies are leading the commercialization of offshore wind energy, ocean thermal gradient, and salinity gradient energy technologies.

\section{OCEAN WAVE ENERGY CONVERSION TECHNOLOGIES}

Ocean waves are generated by the influence of the wind on the ocean surface, which first causes ripples. As the wind continues to blow, the ripples become chop, then fully developed seas, and finally swells. In deep water, the energy in waves can travel for thousands of miles before it is finally dissipated on distant shores.

Many devices have been proposed to achieve the conversion of wave energy into electricity. Various hydraulic or pneumatic power conversion systems are used, and in some cases, the mechanical motion induced by the wave energy is converted directly to electrical power (direct-drive). These devices can be bottom-mounted or floating and vary 

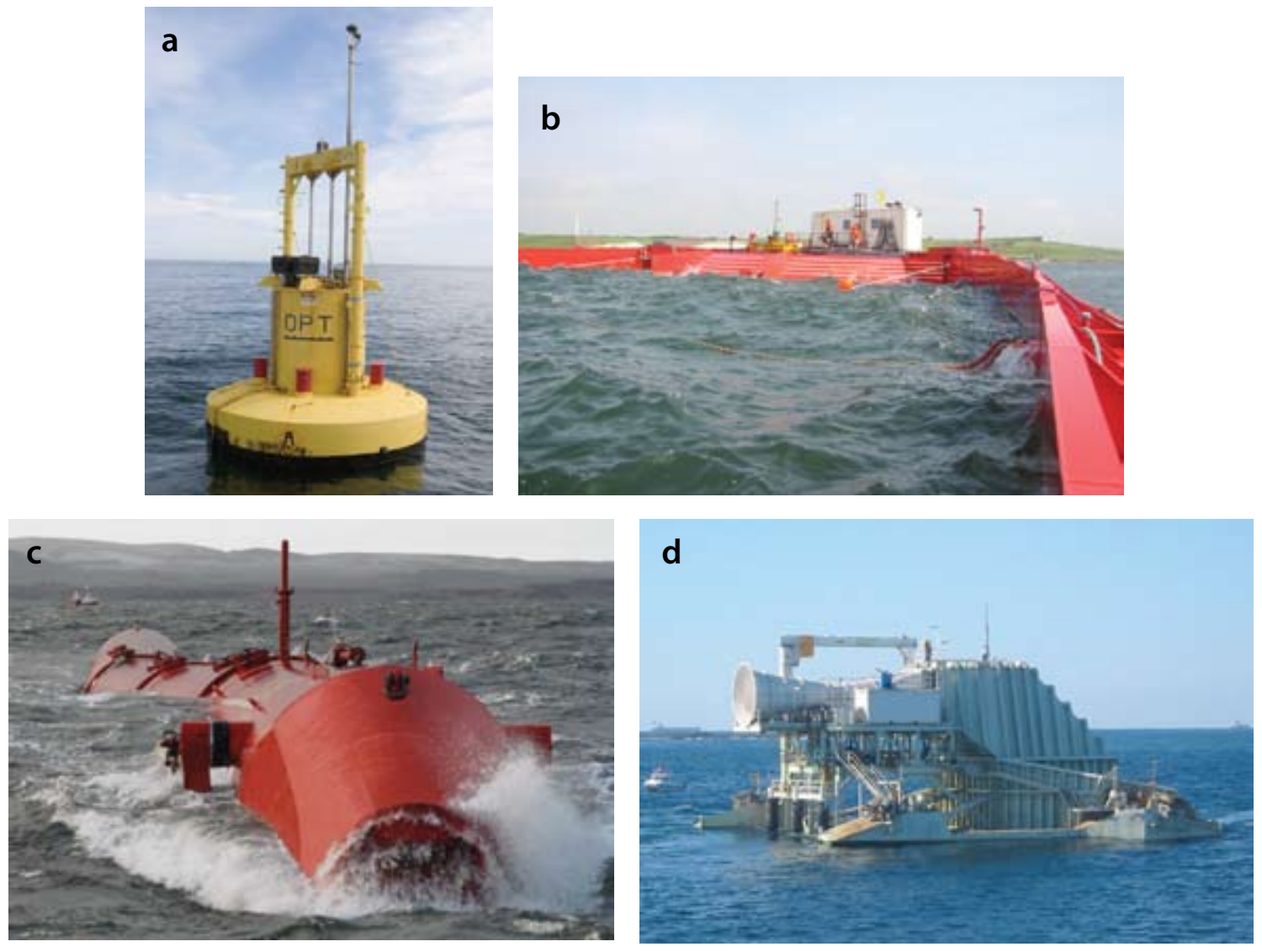

Figure 1. (a) PowerBuoy (courtesy of Ocean Power Technologies), (b) WaveDragon (courtesy of WaveDragon), (c) Pelamis (courtesy of Pelamis Wave Power), and (d) oscillating water column terminator (courtesy of OceanLinx).

in size, orientation, and distance from shore. Four of the best-known offshore technology concepts are introduced below and depicted in Figure 1.

\section{Point Absorber}

Devices that are small compared to a typical wavelength (waves of interest for energy production vary from 40 to over $300 \mathrm{~m}$ in length) are termed "point absorbers." Point absorbers are bottom-mounted or floating structures that absorb energy from all directions. The power conversion system may take a number of forms depending on the selected configuration. Figure 1a shows a floating buoy; however, a point absorber could as well be a bottom-standing device with an upper floater element.

\section{Overtopping Terminator}

A terminator reflects or absorbs all of the wave energy - hence it "terminates" the waves. One type of terminator is an overtopping device that uses a floating reservoir structure, typically with reflecting arms to focus the wave energy (Figure 1b). As waves arrive, they overtop the ramp and are restrained in the reservoir. The potential energy due to the height of collected water above the sea surface then turns conventional lowhead hydro turbines that are coupled to generators to produce electricity.

\section{Linear Absorber or Attenuator} A linear absorber, sometimes called an attenuator, is a device that is large compared to a typical wave's length. The linear absorber structure is oriented roughly parallel to the direction of wave propagation and is composed of multiple

Roger Bedard (rogerbedard@wbhsi.net) is Private Consultant, Palo Alto, CA, USA.

Paul T. Jacobson is Senior Program Manager, Marine and Hydrokinetic Energy Research, Electric Power Research Institute, Palo Alto, CA, USA. Mirko Previsic is President, Re Vision Consulting LLC, Sacramento, CA, USA. Walter Musial is Principal Engineer, National Wind Technology Center, National Renewable Energy Laboratory, US Department of Energy, Boulder, CO, USA. Robert Varley is Program Manager, Lockheed Martin Company, Manassas, VA, USA. 
sections that rotate in pitch and yaw relative to each other. That motion is used to pressurize a hydraulic fluid, which then turns a turbine that is coupled to a generator to produce electricity. Figure 1c depicts a slackly moored, floating, hinged-contour linear absorber. The four sections move relative to each other, and this motion is converted into electricity at each hinge point by a hydraulic power converter system.

\section{Oscillating Water Column}

\section{Terminator}

An oscillating water column (OWC) terminator is a conversion device that harnesses the motion of the ocean waves as they push an air pocket up or pull it down. This device is a partially submerged chamber with air trapped above a column of water (Figure 1d). As waves enter and exit the chamber, the water column moves up and down and acts like a piston on the air, compressing and decompressing it to generate a reversing stream of high-velocity air in an exit blow hole. This air is channeled through a turbine/generator to produce electricity. An OWC is also a type of wave terminator.

\section{STATUS OF OCEAN WAVE ENERGY CONVERSION TECHNOLOGIES}

Today's wave energy conversion technologies are the result of many years of testing, modeling, and development by many organizations. About $4 \mathrm{MW}$ of capacity has been installed to date worldwide, primarily as engineering prototypes. The first shore-based, gridconnected wave power unit was an OWC system built into the coastline of the Island of Islay in Scotland in 2000 by WaveGen (now part of Voith Hydro); the second unit is located on Pico Island, Azores, Portugal. In 2003, WaveDragon was the first offshore, grid-connected wave power unit and was deployed in a protected bay in Denmark due to its subscale nature.

In 2004, Pelamis, the first fullscale, grid-connected wave power unit deployed at sea, was installed at the European Marine Energy Center (EMEC), a wave test facility, in the UK. Based on the successful EMEC testing, the first commercial sale of an offshore wave power plant was announced in May 2005 and the first 2.25-MW stage of that plant was deployed off the coast of Portugal in 2008. ${ }^{1}$

In the United States, Ocean Power Technologies (OPT) was the first to deploy kilowatt-scale wave energy converters off the coasts of Hawai' $i$ and New Jersey in 2005. Columbia Power Technologies (CPT) and Oregon State University (OSU) were the first to deploy kilowatt-scale wave energy converters off the west coast of the United States in 2007 and 2008. OPT plans to deploy a $150-\mathrm{kW}$ point absorber off the coast of Reedsport, Oregon, with construction starting in 2010. CPT's next ocean deployment is planned for late 2010 .

The first nearshore surge-type wave energy converter to deliver electricity to the grid was the Aquamarine Power Oyster, which was mounted to the seabed at a depth of $10 \mathrm{~m}$ at EMEC in late 2009. The surge from passing waves moves a hinged flap, which drives a hydraulic piston to deliver high- pressure water to an onshore turbine that generates electricity.

In the area of testing and test facilities, the US marine energy industry is currently challenged by the lack of proper and standardized infrastructure to deploy and test wave energy conversion devices in the open ocean. However, progress is being made toward the development of such facilities. The Northwest National Marine Renewable Energy Center (NNMREC), led by OSU, will provide wave energy developers with test berths to perform field tests and demonstrations of subscale and full-scale devices. Pacific Gas and Electric (PG\&E) will provide an undersea electrical grid connection called "WaveConnect" several miles offshore of California and will connect wave energy converters from multiple vendors to the PG\&E electrical grid (similar to the UK Wave Hub funded by the UK government) and provide for testing and evaluation of the devices for commercial deployment.

Additional demonstration projects are ongoing and planned in the UK, Ireland, Spain, Portugal, China, Japan, Australia, Canada, and the United States. If these early demonstration schemes prove successful, medium-size wave farms with capacities up to 50-100 MW could be deployed within the next five to ten years.

\section{TIDAL AND OPEN-OCEAN CURRENT ENERGY CONVERSION TECHNOLOGIES}

A tidal current (or hydrokinetic) turbine converts the kinetic energy in a moving mass of water to electricity. The gravitational forces of the sun and the moon on Earth's ocean causes sea

\footnotetext{
1 The major investor in the Pelamis project off the coast of Portugal declared bankruptcy in 2009. The three $750 \mathrm{~kW}$ Pelamis machines are now dockside and awaiting resolution of the financial situation.
} 


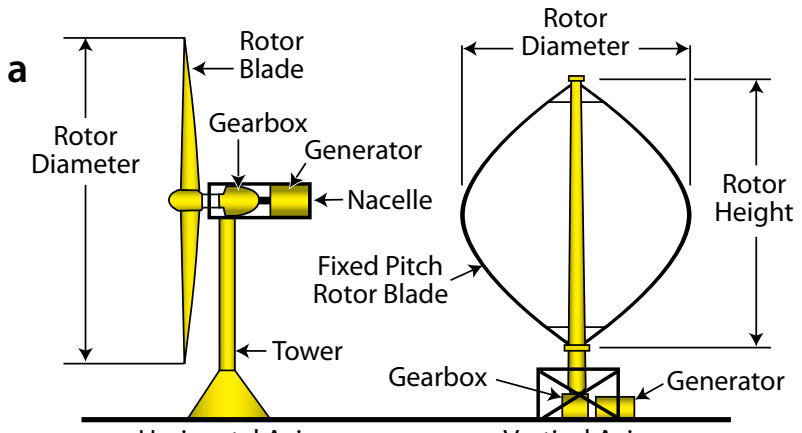

Horizontal Axis

WIND TURBINE CONFIGURATIONS

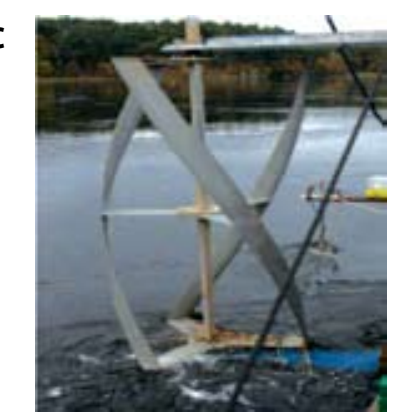

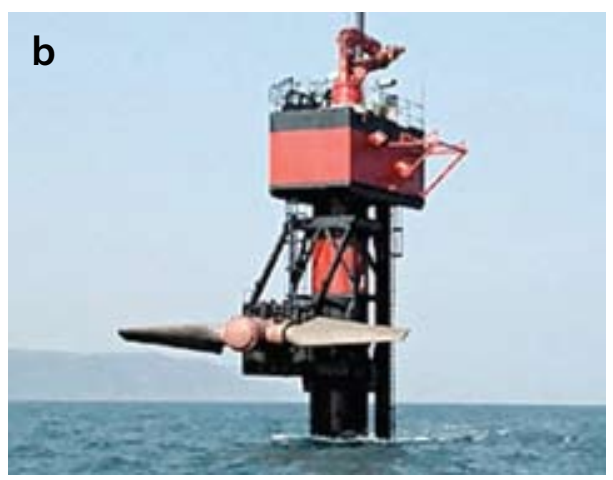

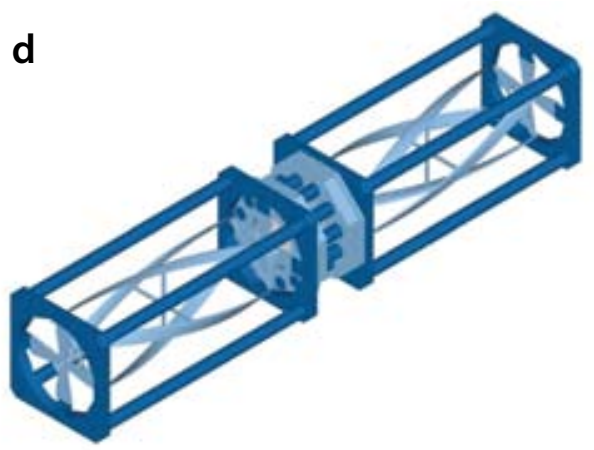

Figure 2. Tidal and open-ocean current energy conversion system configurations. (a) Axial and cross-flow turbines. (b) Axial turbine (courtesy of Marine Current Turbines). (c) Cross flow vertical turbine (courtesy of Lucid Energy). (d) Cross flow horizontal turbine (courtesy of Ocean Renewable Power Company).

level changes, which, in turn, give rise to strong tidal currents when the tide propagates through relative constrictions. Open-ocean currents are the vertical or horizontal movement of both surface and deep water throughout the world ocean caused by Coriolis forces ${ }^{2}$ and thermal gradients. In the Northern Hemisphere, large circular ocean surface currents or gyres move clockwise, and in the Southern Hemisphere, they rotate counterclockwise.

To convert tidal or open-ocean currents to electricity, energy conversion devices are placed in the flowing water stream where they harness the kinetic power of the moving water. Unlike traditional hydroelectric generation or a tidal barrage, they do not require a dam or impoundment.

Similar to wave energy conversion, many devices have been proposed to accomplish the complex conversion of tidal and ocean current energy to electricity. It is helpful to introduce these designs in terms of their physical arrangements and energy conversion mechanisms. Water turbines, like wind turbines, are generally grouped into three types:

1. Axial turbines in which the axis of rotation is parallel to the water stream and thereby horizontal with respect to the seabed

2. Cross-flow turbines in which the axis of rotation is perpendicular to the water stream and may be any angle from horizontal to vertical with respect to the ground

3. Non-turbines, including oscillatory hydrofoils, vortex-induced motion, and hydro venturi devices

Figure 2 illustrates axial and cross-flow types of turbines.

\section{STATUS OF TIDAL IN-STREAM ENERGY CONVERSION TECHNOLOGIES}

The Marine Current Turbine (MCT) 300-kW experimental SeaFlow unit (Figure 2b) was installed in May 2003 and is the world's first marine renewable energy system of significant size to be installed in a genuinely offshore

\footnotetext{
${ }^{2}$ The Coriolis effect is an apparent force that, as a result of Earth's rotation, deflects moving objects (such as projectiles or air and water currents) to the right in the Northern Hemisphere and to the left in the Southern Hemisphere
} 
location. The site is $1 \mathrm{~km}$ off the coast of North Devon, UK.

In the United States, Verdant Power installed an array of six $35-\mathrm{kW}$ gridconnected water turbines in the tidal be installed in 2010 .

US tidal device developers are challenged by the lack of proper and standardized infrastructure to deploy and test tidal energy conversion devices in

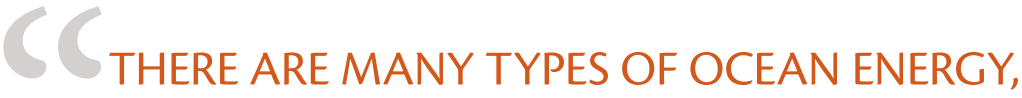 AND THIS IS AN ACTIVE AREA OF RESEARCH AND DEVELOPMENT WITH CONSIDERABLE LONG-TERM PROMISE.}

East River in New York in early 2007.

This experimental project is now complete and Verdant Power has applied to the Federal Energy Regulatory Commission for a license to install 30 tidal turbines in that same location.

In 2008, MCT installed the largest tidal in-stream device to date, a dual, 16-m-diameter rotor SeaGen machine rated at 1.2 MW in Strangeford Narrows in Northern Ireland, an environmentally sensitive site.

OpenHydro of Ireland installed the first tidal in-stream turbine at the EMEC tidal test facility in 2007. The turbine is an experimental 300-kW, 6-m-diameter device that can be lowered for testing and raised above the water line for inspection and servicing on a pair of monopiles. OpenHydro is also testing a gravity base foundation at EMEC. A 1-MW, 10-m-diameter OpenHydro machine was installed in late 2009 at the Nova Scotia Minas Passage Tidal Demonstration project site, and two other 1-MW class machines-one from Marine Current Turbines and the other from Clean Currents-will the tidal passages. The Maine Maritime Academy has proposed a small-scale test facility, and NNMREC's tidal energy branch at the University of Washington is developing plans for a full-scale test facility.

In addition, a number of in-stream tidal demonstration projects are ongoing and planned in the UK, Italy, Korea, Canada, and the United States. If these early undertakings prove successful, arrays up to 1-10 MW in capacity could be deployed within the next five to ten years.

\section{STATUS OF OPEN-OCEAN CURRENT ENERGY CONVERSION TECHNOLOGIES}

In 1977, Aerovironment Inc. conducted preliminary studies to determine the environmental effects of an array of turbines producing 10,000 MW on the Gulf Stream and the surrounding land areas. The program became known as the Coriolis Program, reflecting the fact that it is the Coriolis effect that causes the intensification of the North Atlantic gyre near the Florida Straits. These studies indicated that a 10,000 MW installation would produce a very small reduction in the Gulf Stream speed with no significant adverse side effects, but indicated that more comprehensive studies were needed.

In 2005, the Florida Atlantic University (FAU) Center for Ocean Energy Technology (COET) in Dana Beach, Florida, began a research program to investigate ocean currents as a resource, feasible ways of generating electrical energy from ocean currents, and environmental and ecological interactions. FAU also is developing a platform to support ocean energy technology demonstration, validation, and development.

\section{OFFSHORE WIND ENERGY CONVERSION TECHNOLOGIES}

Offshore, the winds blow stronger and steadier than they do onshore. Consequently, high-wind resource areas are present just a few miles from many of the world's largest urban load centers. Offshore-wind-generated electricity can be used to bring low-carbon energy to many of these cities without the need to build long-distance transmission lines over land.

A wind turbine converts the kinetic energy in the wind to electricity. The major components are a rotor (hub and blades), a gearbox, a generator, and a tower (Figure 3). During the past two decades, land-based wind energy technology has seen a tenfold reduction in cost and is now competitive with fossil and nuclear fuels for electric power generation in many areas of the United States and the world. The offshore wind resource is complementary to the onshore wind resource, and both 
shallow- and deepwater wind resource use is necessary for full offshore wind energy development and deployment.

Offshore wind turbines evolved from onshore wind technology using similar rotors and energy conversion systems. However, several offshore components and systems are different from those used in land-based systems. Machines placed at sea are not constrained by the same transportation and installation limits as onshore machines even though the cost of deploying large vessels at sea is high. The infrastructure and logistical support are significant portions of the system cost for a large offshore wind farm, so offshore machines tend to be larger than land-based turbines. A larger output capacity per unit maximizes the value of the infrastructure, including the cost of foundation and turbine installations, vessels, maintenance, decommissioning, and energy capture potential. Most offshore turbines are now between $3 \mathrm{MW}$ and $5 \mathrm{MW}$ (compared to land-based turbines that range from 1.5 MW to 3.0 MW), and there are several designs underway in the $5-\mathrm{MW}$ to $10-\mathrm{MW}$ range.
Although offshore service records have not been any better than onshore, offshore turbines in the future must be designed for higher reliability and lower maintenance costs. They will be equipped with more advanced condition monitoring, engage more efficient maintenance planning, and be designed to accommodate in situ repair. Offshore machines have different substructures than onshore turbines, requiring ocean engineering skills acquired from the oil and gas industry. Most installations are fixed to the bottom in water depths of 5-25 m, but new designs are extending the technology into deeper waters. The most common substructure is the monopile-a large, thick-walled steel tube (up to $60 \mathrm{~mm}$ thick and $6 \mathrm{~m}$ in diameter). The monopile foundation requires massive hammers to drive the pile into the seabed and special crane vessels for lifting the turbine and tower into place. Gravity-base foundations are also used as an alternative to avoid the need for a large pile-driving hammer or to accommodate areas where piles cannot be reasonably driven. Multipile foundation systems such as tripods are also showing promise for providing alternatives to the conventional monopiles, particularly in deeper water, but higher costs could preclude the widespread deployment of deepwater systems.

Wind turbines are arranged in arrays that take advantage of the measured prevailing wind conditions at the site. Turbine spacing is usually chosen to minimize aggregate power plant power losses, interior plant turbulence, and the cost of cabling between turbines. The wind farm has a power distribution grid that begins by connecting the outputs of the individual turbines at $480 \mathrm{~V}$ to $690 \mathrm{~V}$ through a turbine transformer to a distribution voltage of about $34 \mathrm{kV}$. The electric distribution system collects the power from individual turbines at an electric service platform (ESP), or substation, that provides a common electrical interconnection for all the turbines in the array. At the ESP, the voltage is stepped up to about $138 \mathrm{kV}$ and brought into phase; then the power is transmitted through a number of buried high-voltage subsea cables to shore, where an interconnection point sends the power to the grid. Once onshore, the voltage may need
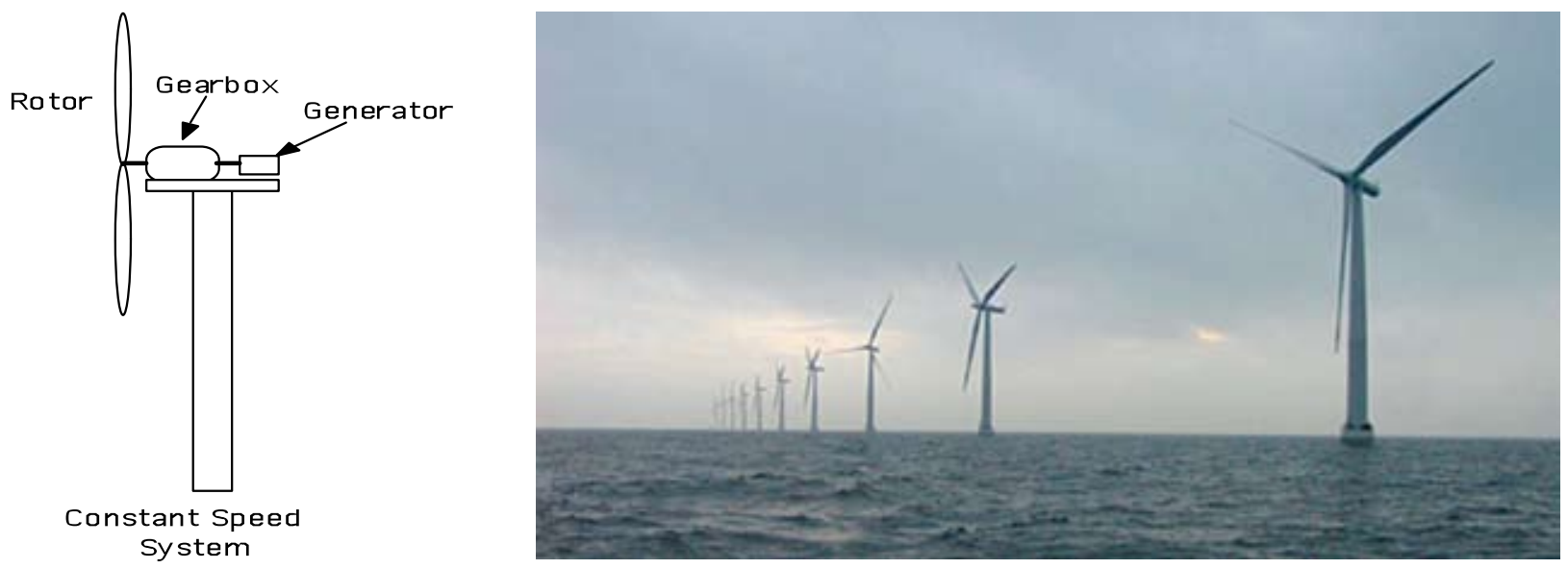

Figure 3. Offshore ocean wind energy conversion. 
to be increased again for power plants larger than $500 \mathrm{MW}$. For smaller arrays that are closer to shore, the distribution grid can extend to the shore for direct connection to a substation and grid system, eliminating the need for an ESP.

The offshore ESP also provides a central service facility for the wind farm, which may include helicopter landing pads, a wind farm control room with supervisory control and data acquisition (SCADA) monitoring stations, a hoist crane for smaller components, a rescue boat, a communication station, firefighting equipment, emergency diesel backup generators, and staff and service facilities, including emergency temporary living quarters for maintenance workers.

\section{STATUS OF OFFSHORE} WIND ENERGY CONVERSION

\section{TECHNOLOGIES}

By the end of 2008, there were

1,471 MW of offshore wind energy collected worldwide with an expected $420 \mathrm{MW}$ added by projects in 2009. The European Union estimates that development is expected in the near future from countries like Germany, where the first commercial offshore wind farms are in process. All told, the EU expects offshore wind development to surge with offshore wind installations generating $150 \mathrm{GW}$ by 2030 .

In the United States, interest in offshore wind is growing rapidly, although no offshore wind turbines have yet been installed. Over 2,000 MW of offshore wind projects are moving through the permitting process and may come online by 2015. Most projects are located in the North and Central Atlantic because the continental shelf has a more gradual drop (compared to the Pacific). This gentle slope allows placement of turbines in federal waters (>3 $\mathrm{nm}$ from shore) while still taking advantage of relatively mature shallowwater technology. In addition, some projects are being proposed in Texas (between Galveston and Mexico) as well as the Great Lakes, and some states have proposed projects in state waters to give themselves greater local control and to speed up the permitting process.

\section{S OCEAN ENERGY TECHNOLOGY DEVELOPERS}

\section{HAVE A VARIETY OF CONVERSION TECHNOLOGIES AT VARIOUS STAGES OF DEVELOPMENT.}

over 1,100 MW of new offshore wind capacity will be added in 2010. China is also in the process of constructing its first $100 \mathrm{MW}$ offshore wind farm near Shanghai. European projects are located mostly in the UK, Denmark, the Netherlands, and Sweden, but strong
Canada has several projects planned as well. Pacific winds exceed Atlantic winds in strength in many places, but offshore wind has not garnered as much enthusiasm from western US states due to the difficulty of installing turbines in the deeper waters.
Currently, installed capital costs for offshore projects are 1.5 to 2.0 times higher than for land-based wind turbines. Factors that contribute to the additional costs include marinizing the turbines for operation at sea, incorporating higher-reliability components, and the at-sea location (e.g., expensive installation vessels, logistics of working at sea, longer power cable to distribution points ashore). In addition, operation and maintenance costs are about three times higher than for land-based systems. This higher cost is partly because accessibility to turbines is more difficult. External conditions are more severe and are more difficult to measure and characterize. Furthermore, extreme wind and wave loads combine to add substantial uncertainty to the nascent design methods used for turbines and substructures.

New technologies to allow floating deepwater deployments have been conceptualized, and engineering design tools are well developed. In June 2009, the Norwegian oil company Statoil launched the first full-scale floating wind turbine. This 2.3-MW demonstration turbine was deployed on a floating spar buoy, and constituted a major industry milestone.

\section{OCEAN THERMAL ENERGY CONVERSION TECHNOLOGIES}

OTEC is the extraction of solar energy via a heat engine operating across the temperature difference between warm surface ocean water and cold deep ocean water. In the tropics, surface water temperatures can exceed $26.7^{\circ} \mathrm{C}\left(80^{\circ} \mathrm{F}\right)$. At ocean depths of $915 \mathrm{~m}(3,000 \mathrm{ft})$, more or less, water temperatures are usually less than $4.4^{\circ} \mathrm{C}\left(40^{\circ} \mathrm{F}\right)$. This temperature differential can drive 
a Rankine thermodynamic cycle to generate electricity. The ideal Carnot efficiency of this small temperature differential is very low. For a system operating between $26.7^{\circ} \mathrm{C}\left(80^{\circ} \mathrm{F}\right)$ and $4.4^{\circ} \mathrm{C}\left(40^{\circ} \mathrm{F}\right)$, the maximum theoretical efficiency is only $7.4 \%$ and real efficiencies will be less. Regardless, Carnot efficiency is not the true measure of OTEC feasibility because "fuel" is free.

OTEC has been technically demonstrated as a feasible method to generate electricity. Figure 4 depicts a closed-cycle OTEC system whereby the working fluid is recirculated within the system. Warm surface ocean water boils a pressurized working fluid in the vaporizer. The vapor expands through a turbine to drive a generator and produce electric power. The expanded vapor is converted back to a liquid in the condenser using cold, deep ocean water. The working fluid pump returns the liquid back to the vaporizer to complete the cycle. Ammonia is one OTEC fluid used because of its thermal properties. Cycle efficiency may be boosted by superheating, reheating, and similar strategies used in steam cycles, though the cost of the added complexity must be offset by any performance gains.

An open-cycle OTEC system uses warm surface ocean water as the working fluid. The warm ocean water is introduced into a vacuum chamber whereby a portion of the water flash evaporates. The low-temperature, low-pressure steam (relative to most existing power plants) expands through the turbine to drive the generator. The expanded vapor is converted back to a liquid in the condenser using cold deep ocean water. The condensed liquid is available as desalinated water. The

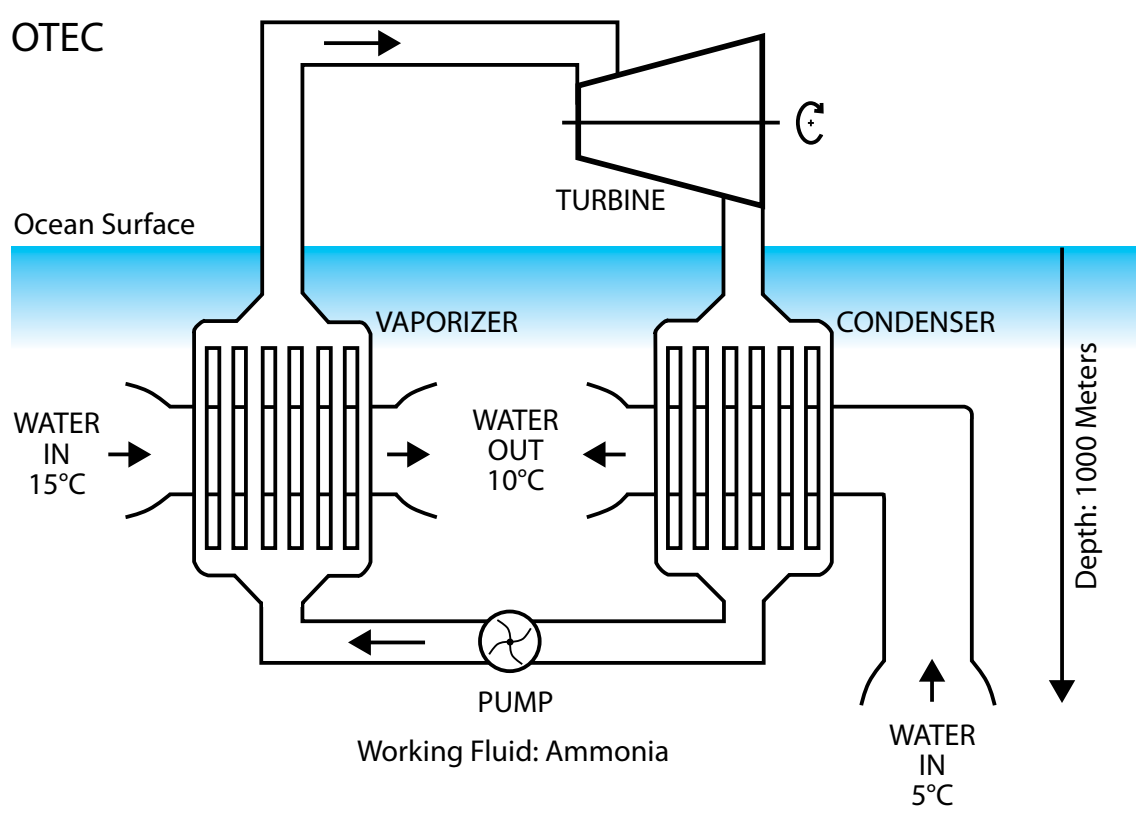

Figure 4. Illustration of ocean thermal energy conversion.

primary disadvantage of the open-cycle system is the very large size and limited capacity of the turbine.

It is possible to combine the flash evaporation and condenser of an opencycle system with a closed-cycle system to produce electric power and desalinated water. This combination is referred to as a hybrid cycle.

The ocean is the solar collector in an OTEC power system. Because this large ocean thermal mass remains relatively constant in temperature, an OTEC power plant provides base load power generation capability that is very attractive to utilities.

Modern-day OTEC studies were supported by the National Science Foundation's (NSF) Research Applied to National Needs program, partly in response to the increase in fossilfuel costs (notably oil) in late 1973. Government direction of the program moved to the Energy Research and Development Administration (ERDA) when that organization was activated in January 1975. Two industry teams developed conceptual designs under the NSF program.

\section{STATUS OF OCEAN THERMAL ENERGY CONVERSION TECHNOLOGIES}

In 1979, a Lockheed team demonstrated net power production from an at-sea closed-cycle OTEC system with the operation of Mini-OTEC off the coast of Hawai' $i$. This plant generated approximately $50 \mathrm{~kW}$ of gross power with about $15 \mathrm{~kW}$ of net power. In 1980, DOE deployed OTEC-1, a converted Navy tanker moored in waters off Hawai'i, to test heat exchangers and other components of a closed-cycle OTEC plant and to investigate the environmental effects of an ocean-stationed OTEC plant. Support for OTEC development waned in the early 1980s when the administration sought to eliminate DOE just as the agency's program was about to fund 
a pilot plant demonstration. Limited

DOE funding survived to support

a test program for heat exchanger

performance, material corrosion, and

biofouling, as well as separate programs
OTEC is the capital cost of the system. OTEC systems exploit a low-energy density resource and therefore need to move large amounts of ocean water to generate utility-scale electric power.

EXCEPT FOR SHALLOW-WATER OFFSHORE WIND, OCEAN ENERGY TECHNOLOGIES ARE STILL IN AN EMERGING STAGE OF TECHNOLOGY DEVELOPMENT, WHERE LAND-BASED WIND TECHNOLOGY WAS APPROXIMATELY 15 TO 25 YEARS AGO.

focused on alternative cold-water pipe designs and gimbal attachments during the 1980s and 1990s.

A number of small companies promote OTEC technology. These companies include Makai Ocean Engineering, Ocean Energy and Engineering Systems International, Sea Solar Power International (now OTEC International), Marine Development Associates, and Offshore Infrastructure Associates. Over the past three years, Lockheed Martin Corporation has restarted its OTEC efforts and, with some of these companies, is developing an OTEC pilot plant and a commercial plant design. DOE has recently supported OTEC development under its Advanced Water Power Project in the Wind and Hydropower Program Office. The Naval Facilities Engineering Command (NAVFAC) awarded an OTEC contract last year to the Lockheed Martin team.

The primary barrier to entry for
Each of the major OTEC subsystems must work together in the most costeffective manner to generate economically viable cost of electricity. Beaudoin et al. (2010) addresses OTEC commercialization barriers.

\section{SALINITY GRADIENT ENERGY CONVERSION TECHNOLOGIES}

When a river runs into the ocean and freshwater mixes with seawater, huge amounts of energy are unleashed. Salinity gradient power, or osmotic power, is the energy retrieved from the difference in the salt concentration between seawater and river water. Two practical methods for this are reverse electro dialysis (RED) and pressure-retarded osmosis (PRO). Both processes rely on osmosis ${ }^{3}$ with ion-specific membranes.

With RED, a salt solution and freshwater pass through a stack of alternating cathode and anode exchange membranes. The chemical potential difference between saltwater and freshwater generates a voltage over each membrane, and the total potential of the system is the sum of the potential differences over all membranes. It is important to remember that the process works through differences in ion concentration instead of an electric field, which has implications for the type of membrane needed. In RED, as in a fuel cell, the cells are stacked. A module with a capacity of $250 \mathrm{~kW}$ is the size of a shipping container.

With PRO, seawater is pumped into a chamber that is separated from a freshwater solution by a semi-permeable membrane. As a result of the osmotic pressure difference between the two solutions, water diffuses through the membrane into the seawater chamber, thereby diluting the seawater and increasing its volume. Pressure compensation in the chamber spins a turbine to generate electricity. Figure 5 is an artist's conception of a PRO plant at sea level.

\section{STATUS OF SALINITY}

GRADIENT ENERGY

\section{CONVERSION TECHNOLOGIES}

Salinity gradient technologies are being developed for commercial use in the Netherlands (for RED) and Norway (for PRO).

A new proposal to improve a 75-year-old dike, the Afsluitdijk, in the Netherlands could make it the world's leading site for generating power using RED technology. The Afsluitdijk is a 32-km-long (20-mile-long) causeway that was constructed in part to dam off the Zuiderzee inlet of the North Sea, turning it into the massive freshwater lake, the IJsselmeer. The lake

${ }^{3}$ Osmosis: Diffusion of fluid through a semi-permeable membrane from a solution with a low solute concentration to a solution with a higher solute concentration until there is an equal concentration of solute on both sides of the membrane. 
periodically discharges water because rivers and streams continually feed it, which makes it an ideal location for the RED saltwater power plant.

Statkraft of Norway has been developing osmotic power since 1997 with a view to achieving cost-effective osmotic power production, making it the world leader in the development of PRO technology. The world's first osmotic power plant was opened in November 2009 at Tofte, outside Oslo, Norway. This plant has been in development for more than a year. It will have a limited production capacity (designed for $10 \mathrm{~kW}$ but initially operating at $2-4 \mathrm{~kW}$ ) and is intended primarily for testing and development purposes. The aim is to be capable of constructing a commercial osmotic power plant within a few years' time.

\section{SUMMARY}

For ocean wave and tidal/ocean current hydrokinetic technology, only several dozen devices have progressed to rigorous subscale laboratory wave-tank or tow-tank model testing. Only a couple of dozen have advanced to short-term (days to months) tests in natural waters. And only a few devices have progressed to long-term ( $>1$ year) testing of fullscale prototypes in natural waters. The first commercial wave energy plant was realized in 2008 in Portugal, and the first commercial tidal current plant or ocean current plant has yet to be realized.

Shallow-water offshore wind is a commercial technology with almost 1,500 MW of capacity installed in Europe. Deep-water offshore wind is an emerging technology, probably

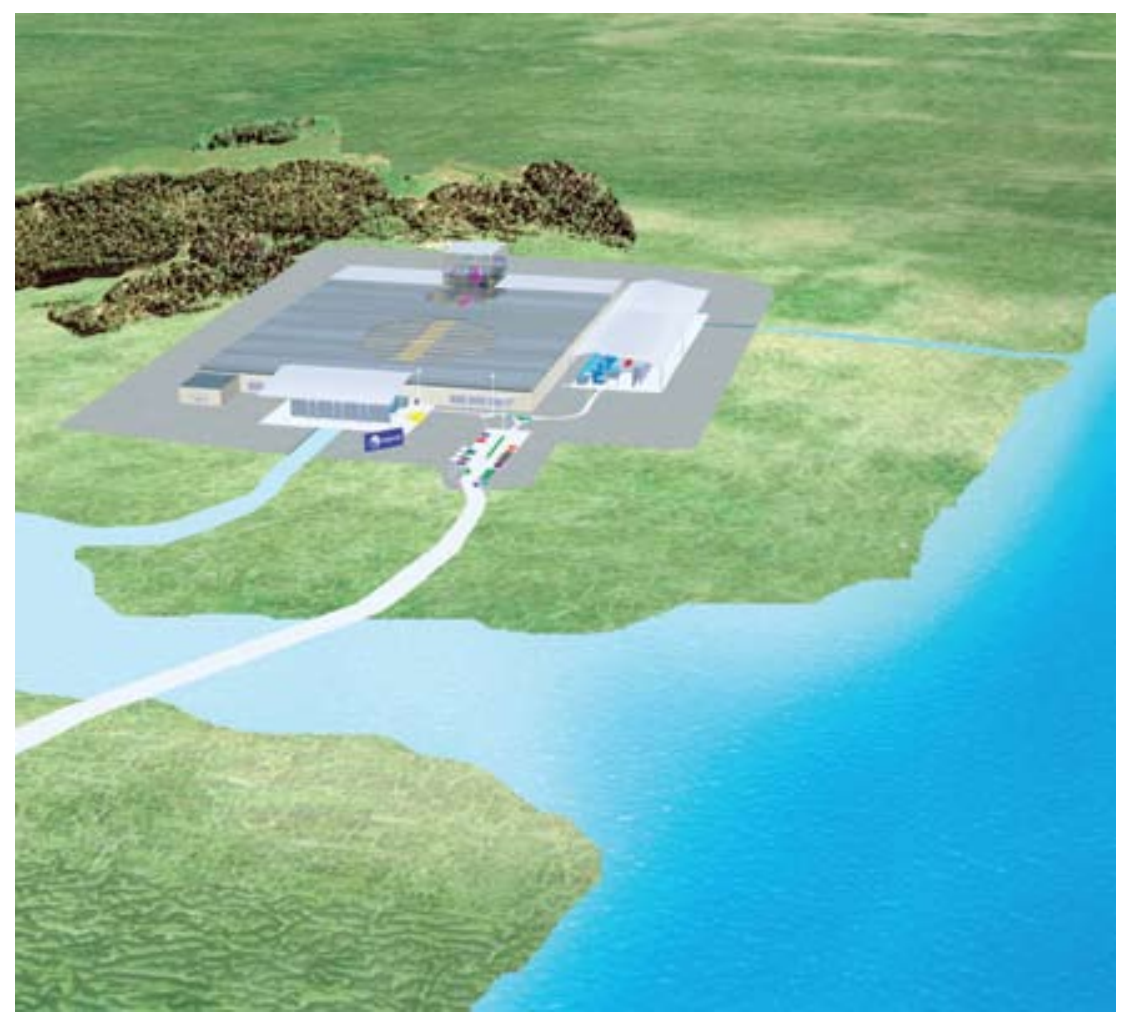

Figure 5. Artist's conception of a pressure-retarded osmosis (PRO) plant placed at sea level. Courtesy of Statkraft

10 to 15 years away from large-scale commercial development. The United States has yet to deploy an offshore wind system.

Eight countries active in OTEC research and development have launched or are planning a number of projects: France, the UK, the Netherlands, Sweden, Norway, Japan, Taiwan, and the United States. There are about 100 nations and territories with access to OTEC thermal resources.

Two countries, the Netherlands and Norway, have active $\mathrm{R} \& \mathrm{D}$ programs in salinity-based electricity generation.

There are many types of ocean energy, and this is an active area of research and development with considerable long-term promise. Ocean energy technology developers have a variety of conversion technologies at various stages of development. The time period needed for these technologies to progress from concept to deployment of a longterm, full-scale prototype in natural waters is on the order of 5 to 10 years. Except for shallow-water offshore wind, ocean energy technologies are still in an emerging stage of technology development, where land-based wind technology was approximately 15 to 25 years ago. It is too early to know which technologies will turn out to be the most cost-effective, reliable, and environmentally sound, which may differ by location. 屃

\section{REFERENCE}

Beaudoin, G., D. Robertson, R. Doherty, D. Corren, B. Staby, and L. Meyer. 2010. Technological challenges to commercial-scale application of marine renewables. Oceanography 23(2):32-41. 